DOI 10.37882/2500-3682.2021.07.12

\title{
К ИСТОРИИ СТАНОВЛЕНИЯ СОЦИАЛЬНОЙ ФИЛОСОФИИ ХХ ВЕКА: ВОКРУГ ДИСКУССИИ ОБ АЗИАТСКОМ СПОСОБЕ ПРОИЗВОДСТВА
}

\section{ON THE HISTORY OF THE FORMATION OF SOCIAL PHILOSOPHY OF THE XX CENTURY: AROUND THE DISCUSSION ABOUT THE ASIAN MODE OF PRODUCTION \\ L. Smetankina A. Ogarkov}

Summary: One of the most difficult problems that arose in the process of the formation of the Marxist theory of socio-economic formations as a typology of history was the problem of correlating the theoretical and empirical levels of historical knowledge, as a specification of the traditional philosophical dispute about the relationship between the categories "general», «special» and «individual». Explication of the content of these categories in social cognition is extremely difficult due to the specificity of the objects of socio-philosophical knowledge, the multiplicity of interpretation options for the concept of «historical fact», the difficulty of separating explanation, description and evaluation in historical research, which is the basis of sociological generalization. In addition, it is often extremely difficult to separate in a conceptual model that «grasps» the totality of social phenomena in their connection, the philosophical aspect of analysis proper from the sociological one, and the sociological aspect from the historical one. The researcher constantly runs the risk of creating such a theoretical construction, which, having delimited the richness of social phenomena with several features, will cease to be a means of cognition, «numb» the fabric of social life.

Such difficulties in the "post-Hegelian» period of the development of philosophy received a radical solution at a new problem level in the concept of G. Rickert: generalizing laws are aimed at finding integrity and the most general signs of its division, to which the historical sciences do not lend themselves at all. The object of history is the individual developmental series.

Keywords: social philosophy, Asian mode of production, discussion, cognition, social life.
Сметанкина Людмила Васильевна

д.ф.н., професссор, ФГКВОУ ВО «Военная академия связи имени Маршала Советского Союза С.М. Буденного» МО РФ,

г. Санкт-Петербург

Ismetankina.umo@mail.ru

Огарков Александр Николаевич

К.ф.н., дочент, ФГБОУ ВО «Санкт-Петербургская государственная художественно-промышленная академия имени А.Л. Штиглица», г. Санкт-Петербург suer53@inbox.ru

Аннотация: Одной из сложнейших проблем, возникших в процессе формирования марксистской теории общественно-экономических формаций как типологии истории, стала проблема соотнесения теоретического и эмпирического уровня исторического познания, как спецификация традиционного философского спора о соотношении категорий «всеобщее», «особенное» и «единичное». Экспликация содержания этих категорий в социальном познании крайне затруднена вследствие специфики объектов социально-философского знания, множественности вариантов интерпретации понятия «исторический факт», трудности отделения объяснения, описания и оценки в историческом исследовании, которое является базой социологического обобщения. К тому же часто крайне трудно бывает отделить в концептуальной модели, «схватывающей» совокупность социальных явлений в их связи, собственно философский аспект анализа от социологического, а социологический - от исторического. Исследователь постоянно рискует создать такую теоретическую конструкцию, которая, отграничив богатство социальных явлений несколькими признаками, перестанет быть средством познания, «омертвит» ткань общественной жизни. Подобные трудности в «постгегелевский» период развития философии получили радикальное разрешение на новом проблемном уровне в концепции Г. Риккерта: генерализирующие законы направлены на отыскание целостности и самых общих признаков ее членения, чему совершенно не поддаются исторические науки. Объектом истории является индивидуальный ряд развития.

Ключевые слова: социальная философия, азиатский способ производства, дискуссия, познание, общественная жизнь.
$\Pi$ опытки рассмотреть закон исторического универсума неизбежно сопровождаются усилиями по отысканию формулы исторического прогресса, между тем как прогресс и регресс - понятия ценности. Как правило, о прогрессе говорят тогда, когда этот критерий ценности уже имеется. Поэтому учение о принципах исторической жизни должно стать учением о системе ценностей (или философией истории). На ценностях базируется историческое познание, они конституируют исторический материал и используются при изложении истории, причем философия истории - не просто классификация ценностей, а критика принципов классификации [1, с. 140-145].

Позже К. Гемпель, М. Мандельбаум, К. Поппер, У. Дрей и вовсе перестали говорить о понятийной системе в историческом познании, сконцентрировав усилия на разрешении проблемы объяснения как логической познавательной операции. Вопрос ставился лишь о применимости научного объяснения к историческим 
наукам. Марксизм же не отделяет, во-первых, научного метода от способов его реализации, во-вторых - принципиально не отделяет историческое знание от научного объяснения. История и есть наука о действительном производстве человеком своей жизни. Речь идет только об уровнях познания этой жизни, определяемых целью исследования.

Марксистская формационная типология фиксирует непрерывность истории, о чем свидетельствует сам характер моделирования исторического процесса, как ряда открытых общественных систем. Все формационные модели однокачественны в том смысле, что в основе типологии лежит один и тот же метод: выделение производственных отношений в качестве системообразующего фактора. И все-таки сам по себе подобный системный анализ имел бы ограниченное методологическое значение, рассматривая лишь социологические модели вне контекста их создания. Жесткость общей схемы последовательности формаций предполагает сравнительно малый и фиксированный набор критериев, по которым определяется место той или иной формационной модели в общем ряду: уровень развития производительных сил, производительность труда, форма собственности, форма эксплуатации. Сами эти понятия строго не обозначены, что определяется спецификой социально-философского знания. Существует и еще одно ограничивающее условие -конкретный уровень исторических знаний, на котором строится социологическая схема. К. Маркс и Ф. Энгельс неоднократно возвращались в своих поздних работах к мысли о «...действительном знании, которое лишает самостоятельную философию ее жизненной среды, в лучшем случае ее может заменить сведение воедино наиболее общих результатов, абстрагируемых из рассмотрения исторического развития. Абстракции эти сами по себе, в отрыве от реальной истории, не имеют ровно никакой ценности. Они могут пригодиться лишь для того, чтобы облегчить упорядочение исторического материала, наметить последовательность отдельных его слоев» $[2$, с. 26].

Трудности «выведения» абстракций и соотнесения их с понятиями исторической науки, знание их методологических пределов, постоянно обновляющийся «фонд» исторических фактов, сама меняющаяся социальная действительность - все эти факторы были причиной возникновения в конце 20-х годов методологически открытой (поскольку она до сих пор не завершена) и крайне полезной для развития социально-философского знания дискуссии об «азиатском способе производства», в которой участвовали представители всех разделов гуманитарного знания. Дискуссии об азиатском способе производства в советской литературе имеют предысторию, которая не эксплицируется в дискуссии, но имеет, на наш взгляд, важное значение для понимания ее смысла, составляя «незримый фон». В 1889 г. в Париже выхо- дит книга брата русского физиолога - Льва Мечникова «Цивилизация и великие исторические реки (Географическая теория прогресса и социального развития)» [3]. Версия возникновения мировой цивилизации, выдвинутая в ней, система аргументов, подтверждающих эту версию, до сих пор сохраняют свое исходное научное значение.

Л.И. Мечников задается целью в исследовании причин возникновения ряда восточных деспотий выйти за пределы нравственного императива (тирания - плохо, демократия - хорошо), выявить объективные причины, по которым ряд древних обществ (египетское, сирийское, индусское, китайское) структурируются в деспотии, могущие быть описанными в одной и той же системе терминов (жесткая «центрированность» общественного целого, надперсональный характер управления, нивелирование роли субъекта). Детально рассматривается регион, в котором формировались три из четырех древних цивилизаций. Констатируется полное единство общих условий, оказавших решающее воздействие во всех трех случаях. Уникальное единство условий выживания (плодороднейший наносный слой ила) и условий, вызывающих необходимость колоссального совместного систематического напряжения (длительные разливы, ручной труд, случайности погоды) привели к созданию единого, централизованного общественного организма, несрабатывание какого-либо из элементов которого означало смерть всего целого. Отсюда - нивелирование роли отдельного лица, независимо от статуса, безусловное подчинение всей его жизни деятельности целого, и в конечном счете - возникновение государства и культуры: «Под страхом неминуемой смерти, река-кормилица заставляла население соединять свои усилия на общей работе, учила солидарности, хотя быв действительности отдельные группы населения ненавидели друг друга. Река налагала на каждого отдельного члена общества некоторую часть общественной работы, полезность которой познавалась впоследствии, а в начале бывала непонятной громадному большинству» [3, с. 162].

В России работу Л.И. Мечникова сразу заметил и оценил Г.В. Плеханов. В работе «История русской общественной мысли» Плеханов использует аргументы концепции Л. Мечникова в своей интерпретации истории России. Согласно его точке зрения (Плеханов опирается на В.О. Ключевского и В.С. Соловьева), особенности расположения и исторического развития России обусловили особый характер ее общественной структуры, представляющей собой сочетание элементов азиатских и европейских обществ. Одним из признаков, сближающих Россию с восточной деспотией, Плеханов называет особые отношения классов, которые были антагонистическими, но не вылились в открытую классовую борьбу, поскольку каждый класс заинтересован в существовании двух других: «...Одной из замечательных особенно- 
стей русского исторического процесса явился тот факт, что наша борьба классов, чаще всего остававшаяся в скрытом состоянии, в течение очень долго времени не только не колебала существовавшего у нас политического порядка, а, напротив, чрезвычайно упрочивала его» [4, с. 112]. Другим существенным признаком «азиатского» характера общественных отношений в России Плеханов считал одинаковую закрепощенность в государстве как низших, так и высших классов, которые состоят на службе у государя. На основании подобной интерпретации российской истории и российского общественного строя Плеханов делает определенные политические выводы относительно аграрной политики большевиков. Против этих аргументов, как и против выводов из них, резко выступил В.И. Ленин на V съезде РСДРП, противопоставив им тезис о капиталистическом характере пореформенных отношений в России.

Доказательства, которые Г.В. Плеханов использовал в своих научных работах для обоснования особого «азиатского» пути развития России, он положил в основу критики аграрной программы большевиков на IV съезде РСДРП: неблагоприятные географические и исторические условия развития России, экономическая необходимость централизации власти и закрепления всех сословий в их одинаковом отношении к государству обусловили особый характер структуры хозяйства и общественного устройства России. Требования большевиков национализировать землю оставляет неизменным «азиатскую» структуру российской экономики, препятствует развитию капитализма в сельском хозяйстве. Требование национализации земли - спекуляция на «психологии уравнения», также сложившейся исторически: «Когда крестьянин, не затронутый революционной пропагандой... говорит о необходимости отобрания земли у помещиков, то ему и в голову не приходит, что он потрясает какие-нибудь основы. Совершенно наоборот! Он считает себя охранителем той экономической основы, которая освящена в его глазах веками, потому что на ней в течение целых веков держалось русское государство... Если бы ему удалось восстановить указанную экономическую основу старого нашего государственного порядка, то сильно, очень сильно повернулось бы назад колесо русской истории» [5, с. 36].

Таким образом, уже к 1906 году «академический» вопрос об «азиатском способе производства» становится вопросом революционной тактики и революционной практики, определяя принципиальные расхождения теоретических платформ двух направлений социал-демократического движения в России. Если меньшевики, во главе с Плехановым, настаивали на принятии буржуазно-демократической программы по аграрному вопросу (муниципализация земли), то большевики ставили целью национализацию земли, с передачей ее после победы революции в собственность всего народа (Проект аграрной программы В.И. Ленина на IV съезде РСДРП).

Своеобразным толчком к официальной дискуссии об «азиатском способе производства» послужил XV съезд ВКП(б) (декабрь 1928 г.) Речь шла об оценке исторического развития Китая с точки зрения определения перспектив классовой борьбы и судеб пролетарской революции в Китае. В отчете Н.И. Бухарина по этому поводу отмечалось: «О китайской революции: рабочий класс должен идти с буржуазией до поворота. Мы накануне нового революционного подъема... В отношении перспектив китайской революции мы не имеем никакого права быть пессимистически настроенными» [6, с. 670]. В прениях по отчету Бухарина выступает Ломинадзе (впоследствии подвергшийся резкой критике на дискуссии 1931 года, организованной марксистским обществом ученых-востоковедов), который совершенно неожиданно в противовес общему ходу и тону съезда и ходу своего выступления заговорил о проблемах формационного анализа, то есть о проблемах сугубо «академических». Согласно его точке зрения, причиной кризиса экономики Китая явился отнюдь не феодализм, очень мало похожий на европейский: «Пережитки этого своеобразного китайского феодализма, который лучше было называть, как Маркс называл, «азиатским способом производства», и являются причиной, порождающей острейшую классовую борьбу в деревне» [6, С. 635]. Указывается особая роль азиатского государства: «...Прежде государство обдирало крестьян как липку, но все же до известной нормы. И при том государство выполняло ряд общественно-полезных функций, без которых сельское хозяйство и торговля Китая не могли бы существовать» [6, с. 735]. Очень характерно, что еще до IV съезда ВКП(б) VI съезд КПК (июнь-июль 1928 года, Москва) отвергает концепцию Ломинадзе на том основании, что китайская действительность не отвечает признакам «азиатского способа производства» (причем признаки перечисляются) $[6$, с. 1074].

На самом же съезде выступление Ломинадзе подверглось жесткой, тщательно подготовленной, с пространным цитированием, критике со стороны П.А. Мифа: «Если Вы, товарищ Ломинадзе, прочитаете мысли Энгельса и Маркса по этому вопросу, вы убедитесь, что Маркс под азиатским способом производства понимал одну из разновидностей феодализма, оговаривая, что по существу никаких отличий от обыкновенного феодализма здесь нет, а есть второстепенные отличия скорее внешнего, отчасти исторического и юридического порядка» $[6$, с. 805]. Миф дал утвердительный ответ на специальный вопрос И.В. Сталина о наличии в Китае буржуазии как класса. В целом такая линия критики азиатского способа производства прослеживается на всем протяжении первой дискуссии.

В 20-е гг. в Советскую Россию приезжает немецкий 
китаевед К. Виттфогель, знакомится со взглядами Маркса и Энгельса на азиатский способ производства, и публикует здесь несколько работ, в том числе и по истории и общественному строю Китая, используя концепцию Мечникова (позже, наряду с К. Марксом и М. Вебером, отцом своей «гидравлической» концепции он называет и Л. Мечникова).

В 1957 г. в США выходит монументальный труд К. Виттфогеля «Восточный деспотизм. Сравнительное исследование тотальной власти» [7]. В этой работе главным структурообразующим фактором восточных обществ называется уже не ирригация, а деспотизм в целом, но тезис о решающем влиянии среды на деспотический характер древних восточных обществ остается неизменным.

Признаки «гидравлической цивилизации»: неограниченная власть правителя, опирающегося на бюрократию; огромная роль государства в экономической жизни общества; слабость общества по сравнению с государством. Жесткие условия «гидравлического хозяйства» ставят общество в ситуацию необходимости немедленного ответа на вызовы природы и рождают различные варианты деспотизма и деспотической культуры, элементы которой переносятся как вирус, заражающий другие общественные организмы. В этой части концепции очевидны заимствования из книги Л. Мечникова, но Виттфогель идет значительно дальше, предполагая возможность сосуществовании гидравлических (деспотических) и негидравлических (западных) цивилизаций. К одному из типов гидравлических обществ он относит СССР и... Турцию (субмаргинальные деспотии). Значение классического политэкономического анализа и вообще традиционного научного аппарата в исследовании гидравлических цивилизаций Виттфогелем отрицается, поскольку, согласно его концепции, современный анализ классов возник в обществе собственников. В гидравлических же обществах отсутствует как таковой институт майората, а собственники обессилены в процессе исторической борьбы за политическую власть государством и бюрократией. Единственное исключение представляет собой западная промышленная цивилизация, возникшая как результат долгой борьбы собственников земли и денег, объединившихся в независимые политические группы, которые дали начало системе политического представительства. В противовес этой западной системе отношение между государственной властью и бюрократией регламентируется только законом «сокращающейся административной отдачи», согласно которому затраты на содержание чиновников не должны превышать

\section{доходов казны.}

Генетический анализ восточных деспотий подготавливает главный вывод книги - о «гидравлическом» азиатском характере государственного устройства России, особо сложном и устойчивом образовании, возникшем в результате совпадения ряда неблагоприятных исторических факторов. Три главы книги: шестая («Ядро, периферия и субмаргинальная область гидравлических обществ»), девятая («Взлет и падение теории азиатского способа производства»), десятая («Восточное общество в движении») посвящены реконструкции истории России и анализу социальной структуры советского государства. Модифицированная концепция Л. Мечникова дополняется выводами Г. Плеханова об азиатском характере русского государства. В целом же логика доказательства такова: Россия, находясь в чрезвычайно неблагоприятных географических и политических условиях (враждебность соседних этносов, с запада скандинавов, с востока - кочевников), вынуждена была путем увеличения жесткости политической структуры, централизации власти, узурпировавшей все права собственности на землю, путем внедрения фискальной системы, заимствованной у монголов, - стать на дуть развития восточной деспотии. Виттфогель использует целый ряд работ русских и советских историков и философов, документы партийных съездов, пытаясь доказать, что аграрная программа большевиков, против которой выступил Плеханов, объективно работала на сохранение азиатских порядков.

Особенность первой дискуссии об «азиатском способе производства» (1928-1934 гг.) - политическая заостренность диспута; признать существование особой азиатской формации (кроме всего прочего) - означало отказаться от точки зрения, согласно которой ряд стран Востока, и прежде всего Китай, вступили в период ускоренного развития феодализма, сопровождаемого обострением всех общественных противоречий и чреватого революционной ситуацией. Но дискуссия, вначале ограниченная предметом (речь шла о «причислении» Китая к феодальной формации и о правомерности использования в практике социологического исследования понятия «азиатский способ производства»), выявила множество «побочных» теоретических проблем: соотношение «всеобщего» и «особенного» в истории; критерий исторического прогресса; специфика внутриформационного анализа; создание формационных моделей рабовладения и феодализма; границы «эмпирического» и «теоретического» уровней исторического исследования.

\section{ЛИТЕРАТУРА}

1. Риккерт Г. Философия истории. - СПб: Изд. Д.Е. Жуковского, 1908. - 158 с. 
2. Маркс К., Энгельс Ф. Немецкая идеология // Соч. - 2-еизд. - Т. 3. - М.: Государственное издательство политической литературы, 1955. - с. 26.

3. Мечников Л.И. Цивилизация и великие исторические реки / Географическая теория прогресса и социального развития/. - М.: Голос труда, 1924. - 255 с.

4. Плеханов Г.В. История русской общественной мысли // Соч.: В 25 т. - М.; Л.: ГИЗ, 1925. - Т. 20. - с.112/.

5. Плеханов Г.В. К аграрному вопросу в России // Соч.: В 25 т. - М.;Л.: ГИЗ, 1924. - Т. 15. - С.36/.

6. XV съезд Всесоюзной коммунистической партии (б): Стенографический отчет. - М.; Л.: Гос. изд-во, 1928. - 1416 с.

7. Wittfogel K. Oriental Despotism. Comparative Study of Total Power. - Hew-Haven, 1956. - 556 /.

○ Сметанкина Людмила Васильевна (Ismetankina.umo@mail.ru), Огарков Александр Николаевич (suer53@inbox.ru).

Журнал «Современная наука: актуальные проблемы теории и практики»

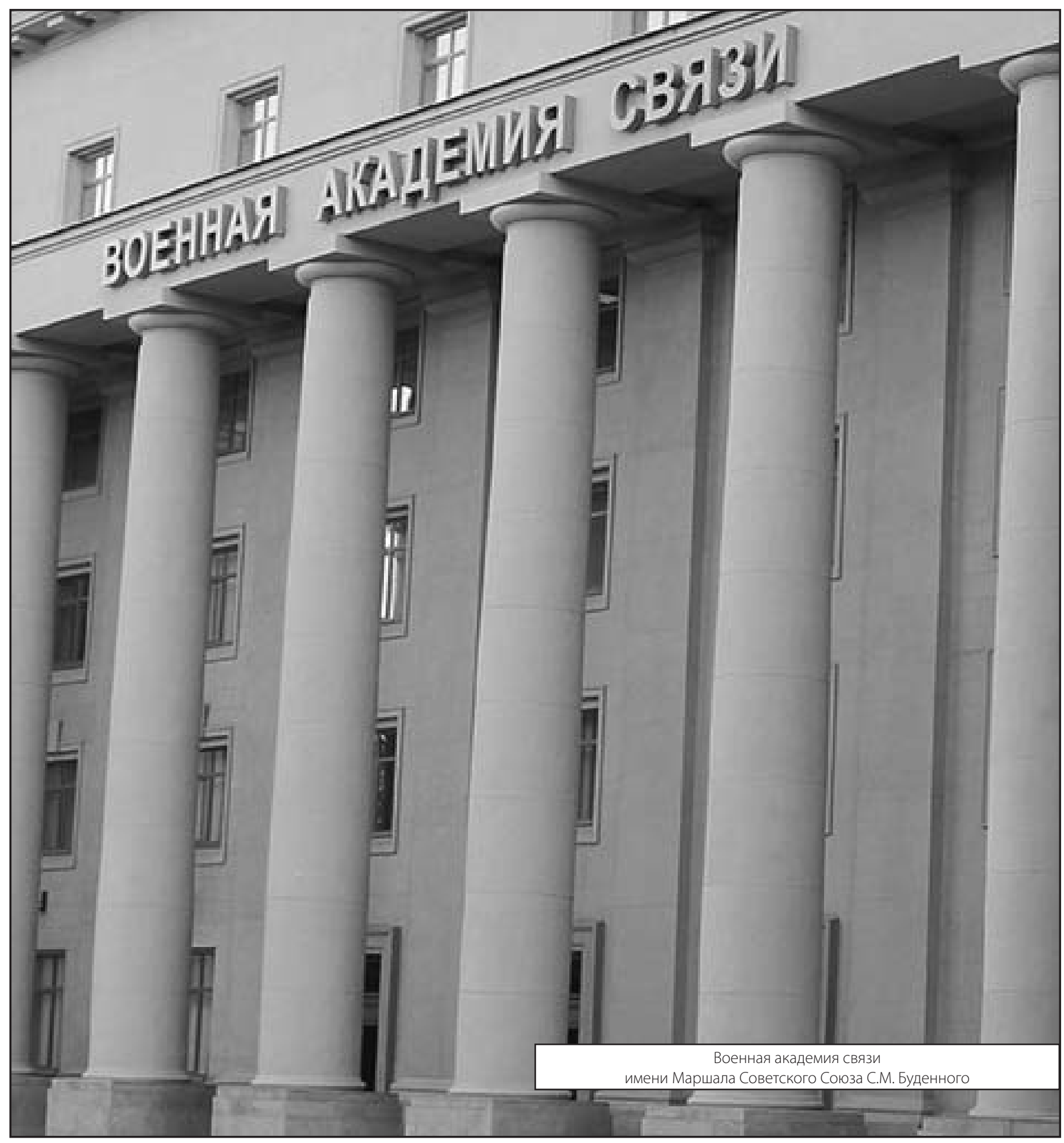

